Check for updates

Cite this: RSC Adv., 2017, 7, 33635

\title{
Manganese dioxide core-shell nanostructure to achieve excellent cycling stability for asymmetric supercapacitor applications
}

\author{
Quanbing Liu, ${ }^{a}$ Juan Yang, ${ }^{b}$ Rongfang Wang, (D) *b Hui Wang ${ }^{b}$ and Shan Ji*ac
}

This study presents a facile and low-cost method to prepare core-shell nano-structured $\beta-\mathrm{MnO}_{2} @ \delta$ $\mathrm{MnO}_{2}$, in which $\beta-\mathrm{MnO}_{2}$ nano-wires act as the cores to form 3D networks and $\delta-\mathrm{MnO}_{2}$ as the shells. A uniform hierarchical $\beta-\mathrm{MnO}_{2} \mathrm{a} \delta-\mathrm{MnO}_{2}$ core-shell structure can be obtained after layered structured $\delta$ $\mathrm{MnO}_{2}$ is deposited on the surface of the needle-like $\beta-\mathrm{MnO}_{2}$ particles via a simple wet chemistry method at room temperature. The as-prepared materials were physically and electrochemically characterized by nitrogen isotherm analysis, X-ray diffraction, scanning electron microscopy, transmission electron microscopy and potentiostatically/galvanostatically. Under our conditions, the electrochemical results showed that the specific capacitance of $\beta-\mathrm{MnO}_{2} \mathrm{Q} \delta-\mathrm{MnO}_{2}$ was $\sim 200 \mathrm{~F} \mathrm{~g}^{-1}$ and the specific capacitance retention was almost $100 \%$ after 5000 cycles at a current density of $1 \mathrm{~A} \mathrm{~g}^{-1}$ in $1 \mathrm{M} \mathrm{LiOH}$ electrolyte. The excellent cycling stability of $\beta-\mathrm{MnO}_{2} \propto \delta-\mathrm{MnO}_{2}$ showed that the new material has great potential for use in electrochemical supercapacitors, and the facile wet chemistry method used to synthesize $\beta-\mathrm{MnO}_{2} \propto \delta-\mathrm{MnO}_{2}$ could be a promising method to produce highly stable $\mathrm{MnO}_{2}$-based electrode materials in large batches.

Received 31st May 2017

Accepted 14th June 2017

DOI: $10.1039 / \mathrm{c} 7 \mathrm{ra06076a}$

rsc.li/rsc-advances dimensional (2D) layered structure and wide interlayer spacing are ideal electrode materials for electrochemical supercapacitors, providing promising features, e.g. favouring the transport of electrolyte ions and the intercalation/ deintercalation processes, leading to highly efficient ESDs. ${ }^{\mathbf{1 1}}$

The capacitance properties of $\mathrm{MnO}_{2}$ strongly rely upon the intercalation/deintercalation of cations into or from its structure in aqueous electrolytes, indicating that structures with large size tunnels or interlayers result in better capacitance performance. ${ }^{10}$ Among all these $\mathrm{MnO}_{2}$ polymorphs, $\delta-\mathrm{MnO}_{2}$ with edge-shared $\mathrm{MO}_{6}$ octahedra have shown to exhibit decent electrochemical performances, making it a promising electrode material for electrochemical supercapacitors; $;^{\mathbf{1 0 , 1 2 , 1 3}}$ this is due to the fact that this polymorph is a two-dimensional layerstructured material with a relatively large interlayer distance ( 7.0 ̊). Recently, many studies have focused on routes and techniques for the preparation of $\delta-\mathrm{MnO}_{2}$. For example, Li et al. reported that $\delta-\mathrm{MnO}_{2}$ synthesized by a microwave-hydrothermal method under low pressure exhibited a specific capacitance of $210 \mathrm{~F} \mathrm{~g}^{-1}$ at a current density of $200 \mathrm{~mA} \mathrm{~g}^{-1}$ in a $1.0 \mathrm{M} \mathrm{Na}_{2} \mathrm{SO}_{4}$ electrolyte. ${ }^{\mathbf{1 4}} \mathrm{Ji}$ et al. deposited hierarchical $\delta-\mathrm{MnO}_{2}$ nano-sheets directly onto a nickel foam substrate using a one-pot chelationmediated aqueous method, and the as-prepared material exhibited a relatively high capacitance of $325 \mathrm{~F} \mathrm{~g}^{-1}$ at a current density of $1 \mathrm{~A} \mathrm{~g} \mathrm{~g}^{-1} \cdot{ }^{15}$ Zhang et al. synthesized $\delta-\mathrm{MnO}_{2} /$ holey graphene hybrid fibre by activating graphene fibre in $\mathrm{a}_{3} \mathrm{PO}_{4}$ solution, followed by the deposition of $\delta-\mathrm{MnO}_{2}$ on its surface. ${ }^{\mathbf{1 6}}$ The electrochemical results showed that the obtained material
${ }^{a}$ School of Chemical Engineering and Light Industry, Guangdong University of Technology, Guangzhou 510006, China. E-mail: jissshan@126.com

${ }^{b}$ Institute of Chemical Engineering, Qingdao University of Science and Technology, Qingdao, 266042, China

${ }^{c}$ College of Biological, Chemical Science and Chemical Engineering, Jiaxing University, Jiaxing, 314001, China 
exhibited a large specific capacitance of $245 \mathrm{~F} \mathrm{~g}^{-1}$ at a current density of $1 \mathrm{~A} \mathrm{~g}^{-1}$ in a $1 \mathrm{M} \mathrm{Na}_{2} \mathrm{SO}_{4}$ solution. Although many efforts have been devoted to the preparation of $\delta-\mathrm{MnO}_{2}$ material for electrochemical supercapacitors, it still remains a challenge to obtain $\delta-\mathrm{MnO}_{2}$ with good cycling capability and stability. This is because (a) these 2D layered nano-structures often result in low electronic properties due to the poor contacts between each other and (b) their crystal structures are not stable under the electrochemical reactions. ${ }^{17,18}$

In order to improve the cycling stability and achieve better electrochemical performance of $\delta-\mathrm{MnO}_{2}$, an alternative and promising way is to develop hierarchical structures using different types of metal oxides. One-dimensional (1D) $\mathrm{MnO}_{2}$ nano-sized materials can provide reliable electrical contact between the $1 \mathrm{D}$ nano-sized $\mathrm{MnO}_{2}$ particles due to the formation of the three-dimensional (3D) network. ${ }^{17} \mathrm{~A}$ hierarchical structure combining a $1 \mathrm{D} \beta-\mathrm{MnO}_{2}$ with a $2 \mathrm{D} \delta-\mathrm{MnO}_{2}$ could result in better electrochemical performances due to (a) the good electrical conductivity of the 1D structure and, (b) the high surface area for ion adsorption on the $2 \mathrm{D}$ architecture improving the diffusion of the charge carriers. Also, there are many rooms in such hierarchical structure which can effectively buffer any volume change during intercalation/deintercalation of cations. ${ }^{19}$

In this study, the authors present a facile and low-cost approach for producing hierarchical core-shell structured mixed phase manganese oxides, consisting of $\beta-\mathrm{MnO}_{2}$ nanowires acting as the core to form $3 \mathrm{D}$ networks and $\delta-\mathrm{MnO}_{2}$ covered on its surface as the shell. In this investigation, the authors had for objective to produce a particle architecture that combines layered structure $\delta-\mathrm{MnO}_{2}$ supported on $\beta-\mathrm{MnO}_{2}$ nano-wires. Through this unusual structural design, the obtained core-shell structured manganese oxide exhibited both high cycling stability and high electrochemical performance.

\section{Experimental}

\subsection{Preparation of the samples}

All reagents were of analytic grade (AR) and double-distilled water was used all throughout the experiments. To prepare the $1 \mathrm{D} \beta-\mathrm{MnO}_{2}$ nano-wires, $8 \mathrm{mmol}$ of $\mathrm{MnSO}_{4}$ and $8 \mathrm{mmol}$ of $\left(\mathrm{NH}_{4}\right)_{2} \mathrm{SO}_{4}$ were added to $60 \mathrm{~mL} \mathrm{H}_{2} \mathrm{O}$ under intense stirring (magnetic stirrer). Then this solution was transferred to a 100 $\mathrm{mL}$ Teflon-lined stainless-steel autoclave and heated at $120{ }^{\circ} \mathrm{C}$ for $12 \mathrm{~h}$. The autoclave was cooled to room temperature, and the product was filtered, washed with water and dried at $80^{\circ} \mathrm{C}$ for $12 \mathrm{~h}$. The resultant material was made of $1 \mathrm{D} \beta-\mathrm{MnO}_{2}$ nanowires.

To prepare $\beta-\mathrm{MnO}_{2} @ \delta-\mathrm{MnO}_{2}, 60 \mathrm{mg}$ of the as-prepared 1D $\beta$ $\mathrm{MnO}_{2}$ nano-wires was added to $30 \mathrm{~mL}$ of $0.41 \mathrm{mmol} \mathrm{MnSO}_{4}$ solution and ultrasonicated for 10 min using an ultrasonic bath operating at $40 \mathrm{kHz}$. The obtained mixture was dropwise added to $20 \mathrm{~mL}$ of $0.28 \mathrm{KMnO}_{4}$ solution and then kept at room temperature for $30 \mathrm{~min}$. Then the product was collected (centrifuge), filtered, washed with water, and finally dried at $80{ }^{\circ} \mathrm{C}$ for $12 \mathrm{~h}$. The obtained product was made of $\beta-\mathrm{MnO}_{2} @ \delta$ $\mathrm{MnO}_{2}$.
For comparison purposes, pure $\delta-\mathrm{MnO}_{2}$ was also prepared and the detail procedure is as follows: $30 \mathrm{~mL}$ of $0.41 \mathrm{mmol}$ $\mathrm{MnSO}_{4}$ was dropwise added to $20 \mathrm{~mL}$ of $0.28 \mathrm{KMnO}_{4}$ solution. The reaction was further allowed to proceed at room temperature for $30 \mathrm{~min}$. The obtained pure $\delta-\mathrm{MnO}_{2}$ was filtered, washed with water and dried at $80{ }^{\circ} \mathrm{C}$ for $12 \mathrm{~h}$.

\subsection{Physical characterizations}

XRD patterns were recorded on a Shimadzu XD-3A (Japan) using filtered $\mathrm{Cu}-\mathrm{K} \alpha$ radiation $(\lambda=0.15418 \mathrm{~nm})$ generated at $40 \mathrm{kV}$ and at $30 \mathrm{~mA}$. Scans for $2 \theta$ values were recorded at $4^{\circ} \mathrm{min}^{-1}$. Scanning electron microscopy (SEM) images were obtained using a Carl Zeiss Ultra Plus. Transmission electron microscopy (TEM) high angle annular dark field scanning transmission electron microscopy (STEM) images and selected area electron diffraction (SAED) patterns of the catalysts were obtained using a JEOL (JEM-2000 FX) microscope operating at $200 \mathrm{kV}$. Linescan energy dispersive spectroscopy (EDS) in the STEM mode was used for elemental composition analysis. The sorption isotherms were obtained on a Quantachrome Autosorb-1 volumetric analyzer. Specific surface areas were determined by the Brunauer-Emmett-Teller (BET) method.

\subsection{Electrochemical characterizations}

Cyclic voltammograms (CV) and galvanostatic charge/discharge experiments on the as-prepared materials were carried out in a three-electrode electrochemical cell. The working electrode (WE) consisted of a film $\left(1 \mathrm{~cm}^{2}\right)$ containing $\beta-\mathrm{MnO}_{2} @ \delta-\mathrm{MnO}_{2}$ (10 mg), carbon black and poly(tetrafluoroethylene) with a mass ratio of $80: 10: 10$, pressed into the Ni foam current collectors. An $\mathrm{Hg} / \mathrm{HgO}(1.0 \mathrm{M} \mathrm{KOH})$ reference electrode (REF) and an activated carbon counter electrode (CE) was used in all experiments in $1 \mathrm{~mol} \mathrm{~L}^{-1} \mathrm{LiOH}$ electrolyte. $\mathrm{CV}$ experiments were performed on a CHI 650D electrochemical workstation. Galvanostatic charge/discharge tests were carried out on a Neware Battery Tester (BTS6.0, Neware Technology Company, Guangdong, China).

\section{Results and discussion}

Fig. 1 shows the powder X-ray diffraction (XRD) patterns of $\beta$ $\mathrm{MnO}_{2}, \delta-\mathrm{MnO}_{2}$ and $\beta-\mathrm{MnO}_{2} @ \delta-\mathrm{MnO}_{2}$. The XRD pattern of $\beta$ $\mathrm{MnO}_{2}$ shows the typical peak dispersion indexed to $\beta-\mathrm{MnO}_{2}$ tetragonal phase (Joint Committee on Powder Diffraction Standards [JCPDS] Card 24-0735), in which no peaks related to other types of $\mathrm{MnO}_{2}$ or amorphous $\mathrm{MnO}_{2}$ are observed, indicative of the formation of highly pure and crystalline $\beta-\mathrm{MnO}_{2}$. The diffraction peaks of $\delta-\mathrm{MnO}_{2}$, synthesized at room temperature, are exhibited at angles of $37.2^{\circ}$ and $67.2^{\circ}$ which are ascribed to (111) and (021) planes of $\delta-\mathrm{MnO}_{2}$ (JCPDS Card: 421317) respectively. However, these peaks are small and weak, indicating that the as-prepared $\delta-\mathrm{MnO}_{2}$ particles are small and poorly crystalline. Similar XRD patterns of $\delta-\mathrm{MnO}_{2}$ were also found in the literature where the $\delta-\mathrm{MnO}_{2}$ samples were prepared at low temperature. ${ }^{15,20,21}$ In the case of $\beta-\mathrm{MnO}_{2} @ \delta$ $\mathrm{MnO}_{2}$, its XRD pattern shows no obvious difference from $\beta$ - 


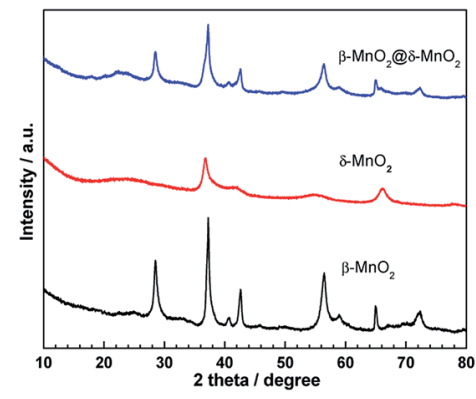

Fig. 1 XRD patterns of $\beta-\mathrm{MnO}_{2}, \delta-\mathrm{MnO}_{2}$ and $\beta-\mathrm{MnO}_{2} @ \delta-\mathrm{MnO}_{2}$.

$\mathrm{MnO}_{2}$, for example the peaks resemble to those associated to a $\beta-\mathrm{MnO}_{2}$ structure indicating that a small amount of $\delta-\mathrm{MnO}_{2}$ was formed on the surface of $\beta-\mathrm{MnO}_{2}$.

Scanning electron microscope (SEM) and transmission electron microscope (TEM) images of $\beta-\mathrm{MnO}_{2}$ and $\beta-\mathrm{MnO}_{2} @ \delta$ $\mathrm{MnO}_{2}$ are shown in Fig. 2(A). shows that the as-prepared $\beta$ $\mathrm{MnO}_{2}$ particles are needle-like in shape and have a size of $c a$. 2$5 \mu \mathrm{m}$ in length by direct statistic observation. The figure also shows that there is no presence of other forms of particles, indicating that highly pure $\beta-\mathrm{MnO}_{2}$ with uniform morphology was formed, which is in very good agreement with the XRD results. SEM image of $\delta-\mathrm{MnO}_{2}$ is shown in Fig. 2(C), which comprise irregular particles and many particles aggregated into large particles. As shown in Fig. 2(B), a uniform hierarchical $\beta$ $\mathrm{MnO}_{2} @ \delta-\mathrm{MnO}_{2}$ core-shell structure was formed after the $\delta$ $\mathrm{MnO}_{2}$ was deposited on the surface of $\beta-\mathrm{MnO}_{2}$ via the simple

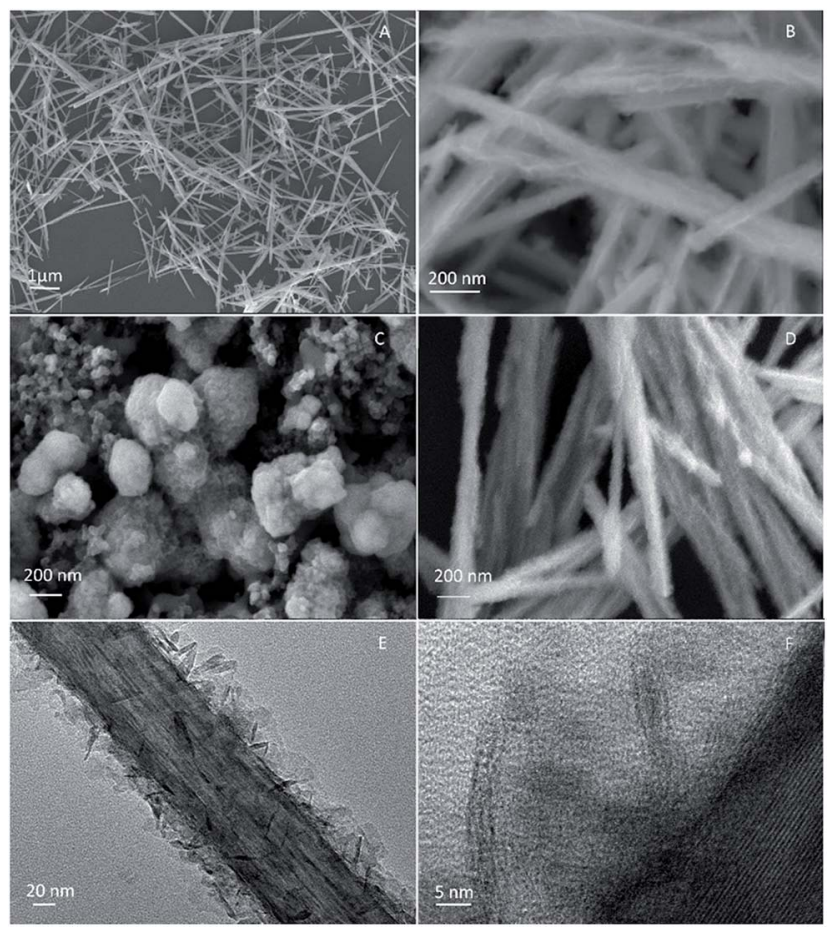

Fig. 2 SEM images of $\beta-\mathrm{MnO}_{2}(\mathrm{~A}), \beta-\mathrm{MnO}_{2} \propto \delta-\mathrm{MnO}_{2}(\mathrm{~B}), \delta-\mathrm{MnO}_{2}$ (C) and $\beta-\mathrm{MnO}_{2} \propto \delta-\mathrm{MnO}_{2}$ after 5000 cycles (D), TEM image of $\beta$ $\mathrm{MnO}_{2} @ \delta-\mathrm{MnO}_{2}(\mathrm{E})$ and HRTEM image of $\beta-\mathrm{MnO}_{2} @ \delta-\mathrm{MnO}_{2}(\mathrm{~F})$. wet chemistry method at room temperature. From the figure, it can be seen that the $\delta-\mathrm{MnO}_{2}$ is hardly formed in the spaces between the $\beta-\mathrm{MnO}_{2}$ nano-wires, implying that the formation of $\delta-\mathrm{MnO}_{2}$ preferentially occurs on the surface of $\beta-\mathrm{MnO}_{2}$ nanowires resulting in an uniform $\beta-\mathrm{MnO}_{2} @ \delta-\mathrm{MnO}_{2}$ core-shell structure. Fig. 2(E) shows a typical TEM image of $\beta-\mathrm{MnO}_{2} @ \delta$ $\mathrm{MnO}_{2}$. The figure shows that the $\beta-\mathrm{MnO}_{2}$ has a uniform nanowire structure with a diameter of $c a .70 \mathrm{~nm}$. It can also be seen that $\delta-\mathrm{MnO}_{2}$ was uniformly distributed on the surface of $\beta$ $\mathrm{MnO}_{2}$ nano-wires with a thickness of $c a .30 \mathrm{~nm}$. However, there is no obvious evidence of boundaries between the $\beta-\mathrm{MnO}_{2}$ core and $\delta-\mathrm{MnO}_{2}$ shell, showing that an intimate contact between these two different phases of $\mathrm{MnO}_{2}$ exists. On the edge of the $\delta$ $\mathrm{MnO}_{2}$ shell, ultra-thin $\delta-\mathrm{MnO}_{2}$ nano-sheets are found and expected to provide improved electrochemical properties. Fig. 2(F) shows a detailed microstructure of the core and shell of $\beta$ $\mathrm{MnO}_{2} @ \delta-\mathrm{MnO}_{2}$, in which the atomic plane arrangement of $\beta$ $\mathrm{MnO}_{2}$ is clearly present, but with the absence of an atomic plane in the shell of $\delta-\mathrm{MnO}_{2}$. This finding further confirms that the $\delta$ $\mathrm{MnO}_{2}$ grown on the surface of $\beta-\mathrm{MnO}_{2}$ is small and is of a poor crystalline structure. It is also observed that the $\delta-\mathrm{MnO}_{2}$ shell with layered structure was formed on the surface of $\beta-\mathrm{MnO}_{2}$ nano-wires. Such a layered structure is expected to facilitate the intercalation/deintercalation of cations into and from the electrode materials resulting in an improved electrochemical capacitance performance.

The porous structures of $\beta-\mathrm{MnO}_{2}, \delta-\mathrm{MnO}_{2}$ and $\beta-\mathrm{MnO}_{2} @ \delta$ $\mathrm{MnO}_{2}$ were evaluated by $\mathrm{N}_{2}$ isotherm analysis (Fig. 3 and Table 1). The nitrogen adsorption-desorption isotherms of $\beta$ $\mathrm{MnO}_{2}$, shows a type II isotherm (as defined by the International Union of Pure and Applied Chemistry (IUPAC)) with a sharp capillary condensation step at a relative high pressure $\left(P / P_{0}>\right.$ 0.85). An hysteresis loop between adsorption and desorption curve could be considered as an H4-type, indicating a relatively large pore size, which could be due to the slit-shaped gap among the $\mathrm{MnO}_{2}$ crystals. ${ }^{22}$ The isotherm of $\beta-\mathrm{MnO}_{2} @ \delta-\mathrm{MnO}_{2}$ also exhibits type II with a hysteresis loop at a high relative pressure, indicating that the as-prepared material is of a mesoporous nature. The isotherms of $\delta-\mathrm{MnO}_{2}$ is a mixed type in the IUPAC classification with a type I at a relative low pressure and a type II with an hysteresis loop at a relative intermediate and high pressure. ${ }^{23}$ At the initial part, there is an obvious uptake at a low relative pressure, which is a characteristic of a microporous structure. As shown in Fig. 3(B), the pore size distributions calculated from the Barrett-Joyner-Halenda (BJH) method show that the pore size distributions of $\delta-\mathrm{MnO}_{2}$ and $\beta-\mathrm{MnO}_{2} @ \delta$ -
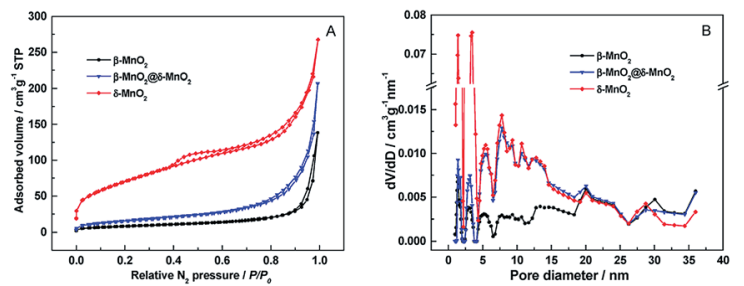

Fig. $3 \quad \mathrm{~N}_{2}$ isotherms (A) and pore size distribution (B) of $\beta-\mathrm{MnO}_{2}, \delta$ $\mathrm{MnO}_{2}$ and $\beta-\mathrm{MnO}_{2} @ \delta-\mathrm{MnO}_{2}$. 
Table 1 Porous structure of $\beta-\mathrm{MnO}_{2}, \delta-\mathrm{MnO}_{2}$ and $\beta-\mathrm{MnO}_{2} @ \delta-\mathrm{MnO}_{2}$

\begin{tabular}{lcl}
\hline Samples & BET $\left(\mathrm{m}^{2} \mathrm{~g}^{-1}\right)$ & Pore volume $\left(\mathrm{cm}^{3} \mathrm{~g}^{-1}\right)$ \\
\hline$\beta-\mathrm{MnO}_{2}$ & 30.06 & 0.214 \\
$\beta-\mathrm{MnO}_{2} @ \delta-\mathrm{MnO}_{2}$ & 56.44 & 0.321 \\
$\delta-\mathrm{MnO}_{2}$ & 248.91 & 0.414 \\
\end{tabular}

$\mathrm{MnO}_{2}$ are in the mesopore size range with a few micropores present. The BET surface area of $\delta-\mathrm{MnO}_{2}$ was found to be 248.91 $\mathrm{m}^{2} \mathrm{~g}^{-1}$, which is $\sim 8$ times higher than that of $1 \mathrm{D} \beta-\mathrm{MnO}_{2}(30.06$ $\mathrm{m}^{2} \mathrm{~g}^{-1}$ ). After $\delta-\mathrm{MnO}_{2}$ was grown on the surface of needle-like 1D $\beta-\mathrm{MnO}_{2}$, the BET surface area of $\beta-\mathrm{MnO}_{2} @ \delta-\mathrm{MnO}_{2}$ was determined to be $56.44 \mathrm{~m}^{2} \mathrm{~g}^{-1}$, which is almost twice as high as that of $\beta-\mathrm{MnO}_{2}$, but still much lower than that of $\delta-\mathrm{MnO}_{2}$, due to the presence of a thin layer of $\delta-\mathrm{MnO}_{2}$ grown on $\beta-\mathrm{MnO}_{2}$.

The electrochemical performance of the as-prepared $\beta$ $\mathrm{MnO}_{2}, \delta-\mathrm{MnO}_{2}$ and $\beta-\mathrm{MnO}_{2} @ \delta-\mathrm{MnO}_{2}$ was evaluated by cyclic voltammetry (CV) and galvanostatic charge-discharge experiments in a three-electrode cell configuration and in $1 \mathrm{~mol} \mathrm{~L}^{-1}$ LiOH electrolyte. Fig. 4(A) shows the CVs of the $\beta-\mathrm{MnO}_{2}, \delta-\mathrm{MnO}_{2}$ and $\beta-\mathrm{MnO}_{2} @ \delta-\mathrm{MnO}_{2}$ electrodes at a scan rate of $5 \mathrm{mV} \mathrm{s}{ }^{-1}$ in 1.0 $\mathrm{M} \mathrm{LiOH}$ solution and at room temperature. The figure shows that the CVs for the three samples exhibit a quasi-rectangular shape, typical of a pseudo-capacitive behaviour, with pairs of redox peaks corresponding to the reversible Faradaic redox reactions. The charge storage of $\mathrm{MnO}_{2}$-based electrodes results from the adsorption/desorption and the intercalation/ deintercalation of cations or protons of the electrolyte. ${ }^{11}$ The morphology, crystal structure and surface area play an important role in storing the charges. The current response on $\delta$ $\mathrm{MnO}_{2}$ is the highest among these three electrodes, suggesting that the high surface area and the layered structure favour the intercalation/deintercalation process as well as the adsorption/ desorption occurring on the surface. On the $\beta-\mathrm{MnO}_{2} @ \delta-\mathrm{MnO}_{2}$
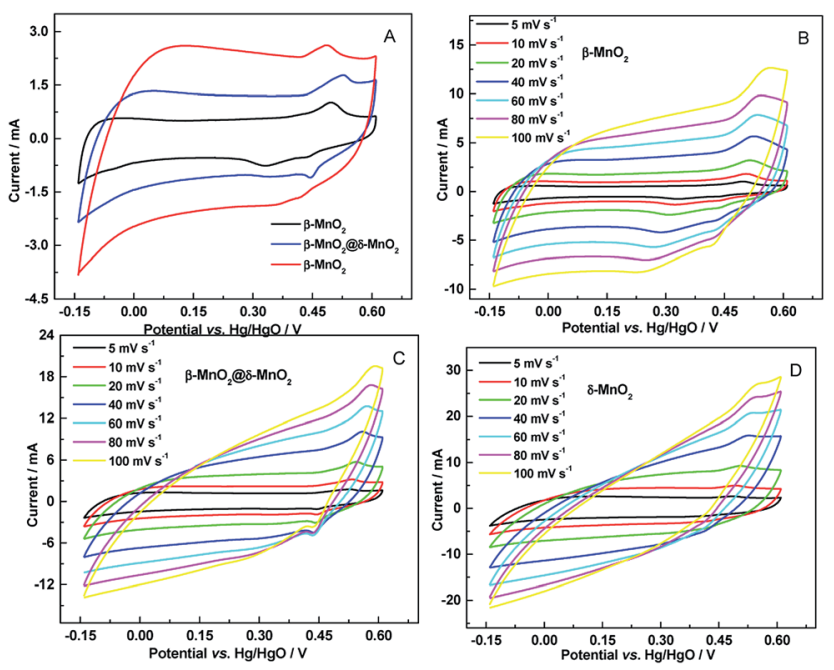

Fig. 4 (A) $C V s$ of $\beta-M n O_{2}, \delta-M n O_{2}$ and $\beta-M n O_{2} \propto \delta-M n O_{2}$ electrodes at scan rate of $5 \mathrm{mV} \mathrm{s}^{-1}$ and $(\mathrm{B}-\mathrm{D})$ their corresponding $\mathrm{CVs}$ at various scan rates $\left(5-100 \mathrm{mV} \mathrm{s}^{-1}\right)$ in $1 \mathrm{M} \mathrm{LiOH}$. electrode, the current response is higher than that of the $\beta$ $\mathrm{MnO}_{2}$ electrode, indicating additional capacitive contribution from $\delta-\mathrm{MnO}_{2}$ after it had been deposited on the surface of $\beta$ $\mathrm{MnO}_{2}$. Fig. 4(C) and (D) show the CVs of $\beta-\mathrm{MnO}_{2}, \delta-\mathrm{MnO}_{2}$ and $\beta$ $\mathrm{MnO}_{2} @ \delta-\mathrm{MnO}_{2}$ electrodes carried out over the potential range of -0.15 to $+0.60 \mathrm{~V} v s$. $\mathrm{Hg} / \mathrm{HgO}$ at various scan rates $(5-100 \mathrm{mV}$ $\mathrm{s}^{-1}$ ). When the scan rate increases from 5 to $100 \mathrm{mV} \mathrm{s}^{-1}$, the CVs of $\beta-\mathrm{MnO}_{2}$ still retain a quasi-rectangular shape, even though the Faradaic process revolves around the electrochemical behaviour of $\beta-\mathrm{MnO}_{2}$ in $1 \mathrm{M} \mathrm{LiOH}$ electrolyte, implying that the adsorption/desorption process dominates the charge storage process in $\beta-\mathrm{MnO}_{2}$. In the case of $\delta-\mathrm{MnO}_{2}$ and $\beta-\mathrm{MnO}_{2} @ \delta$ $\mathrm{MnO}_{2}$, due to the layered structure of $\beta-\mathrm{MnO}_{2}$, the Faradaic process contributed proportionately more to the charge storage than the electrical double-layer capacitance. Therefore, with increasing the scan rate, the $\mathrm{CVs}$ of $\delta-\mathrm{MnO}_{2}$ and $\beta-\mathrm{MnO}_{2} @ \delta$ $\mathrm{MnO}_{2}$ exhibit a distortion/change from quasi-rectangular shape due to electrode polarization. At fast scan rates, there is barely time for some $\mathrm{Li}^{+}$ions to intercalate into the $\mathrm{MnO}_{2}$ structure due to the polarization of the desolvation process of $\mathrm{Li}^{+}$ions, resulting in the CVs deviating from the quasi-rectangular shape. ${ }^{24}$

Fig. 5 shows the galvanostatic charge-discharge curves of the $\beta-\mathrm{MnO}_{2}, \delta-\mathrm{MnO}_{2}$ and $\beta-\mathrm{MnO}_{2} @ \delta-\mathrm{MnO}_{2}$ at a current density of $50 \mathrm{~mA} \mathrm{~g}{ }^{-1}$. All three electrodes present non-linear charge curves, asymmetric to their corresponding discharge curves (as shown in Fig. 5(A)), which is commonly and typically observed for pseudo-capacitive materials. ${ }^{25}$ The charge-discharge curves exhibit a quasi-plateau over the potential range from +0.3 to $+0.5 \mathrm{~V} v s$. $\mathrm{Hg} / \mathrm{HgO}$. This quasi-plateau could originate from the intercalation/deintercalation of $\mathrm{Li}^{+}$into or from $\mathrm{MnO}_{2}$ structure which is consistent with the CV curves. The specific capacitance $\left(C_{\mathrm{s}}\right)$ values derived from the discharge curves were calculated using the following equation:

$$
c(F / g)=\frac{I \Delta t}{m \Delta V}
$$
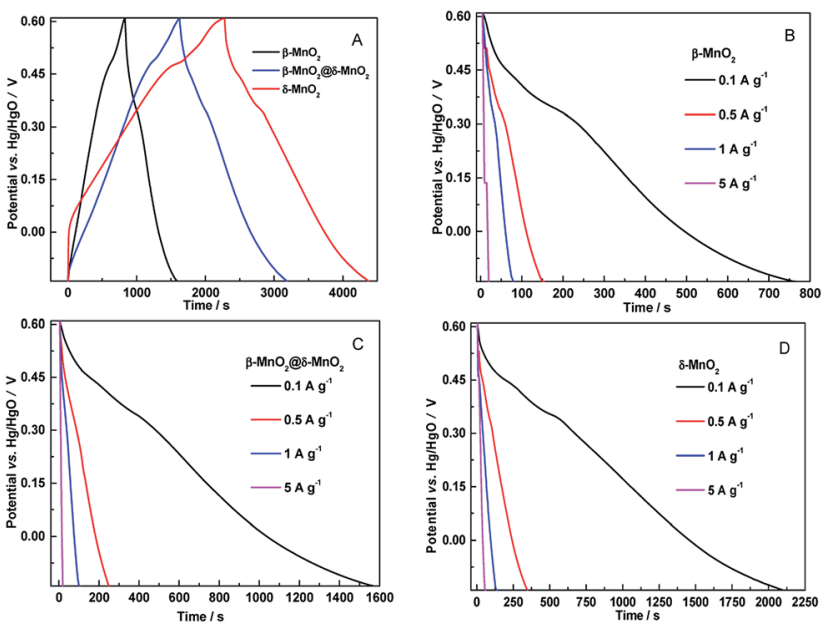

Fig. 5 Galvanostatic charge-discharge curves of the $\beta-\mathrm{MnO}_{2}$, $\delta$ $\mathrm{MnO}_{2}$ and $\beta-\mathrm{MnO}_{2} \propto \delta-\mathrm{MnO}_{2}$ at a current density of $50 \mathrm{~mA} \mathrm{~g}{ }^{-1}(\mathrm{~A})$, discharge curves of $\beta-\mathrm{MnO}_{2}$ (B), $\beta-\mathrm{MnO}_{2}\left(\mathrm{\alpha} \delta-\mathrm{MnO}_{2}(\mathrm{C})\right.$ and $\delta-\mathrm{MnO}_{2}$ (D) electrodes at various current densities. 
where $I$ is the sampled current, $t$ is the sampling time span, $V$ is the total potential deviation of the potential window, and $m$ is the mass of the active electrode material. $C_{\mathrm{s}}$ discharge values of $\beta-\mathrm{MnO}_{2}, \delta-\mathrm{MnO}_{2}$ and $\beta-\mathrm{MnO}_{2} @ \delta-\mathrm{MnO}_{2}$ were found to be 100.3, 246.9 and $200.8 \mathrm{~F} \mathrm{~g}^{-1}$ respectively. The increase in $C_{\mathrm{s}}$ from the $\beta$ $\mathrm{MnO}_{2}$ to $\delta-\mathrm{MnO}_{2}$ indicates that the layered structure $\delta-\mathrm{MnO}_{2}$ with high surface area contributed to $C_{\mathrm{s}}$ in correlation with the $\mathrm{CV}$ results. Rate capability testing of $\beta-\mathrm{MnO}_{2}, \delta-\mathrm{MnO}_{2}$ and $\beta$ $\mathrm{MnO}_{2} @ \delta-\mathrm{MnO}_{2}$ was evaluated at current densities ranging from $0.1 \mathrm{~A} \mathrm{~g}^{-1}$ to $5 \mathrm{~A} \mathrm{~g}^{-1}$ and the data are shown in Fig. 5(C and D). The results of rate capability experiments show that the specific capacitance decreased with increased current density, which is in good agreement with reported literature on $\mathrm{MnO}_{2}$-based electrodes. 4,26,27 When the current density increases from beyond $0.5 \mathrm{~A} \mathrm{~g}^{-1}$, the quasi-plateau gradually disappears owing to the incomplete intercalation/deintercalation process.

The effect of the current density on the specific capacitance of $\beta-\mathrm{MnO}_{2}, \delta-\mathrm{MnO}_{2}$ and $\beta-\mathrm{MnO}_{2} @ \delta-\mathrm{MnO}_{2}$ is shown in Fig. 6. It is clearly evident from the figure that the $C_{\mathrm{s}}$ for all three samples gradually decreased when the current densities increased from 0.05 to $5 \mathrm{~A} \mathrm{~g}^{-1}$. At the low current densities, all three electrodes show relatively high capacitance since the electrolyte ions have enough time to move to the interface of the electrode/electrolyte and take part to the intercalation/deintercalation process. At a current density of $5 \mathrm{~A} \mathrm{~g}^{-1}$, only a small portion of the material close to the surface can be utilized for storing the charge. The $C_{\mathrm{s}}$ of $\beta-\mathrm{MnO}_{2}, \delta-\mathrm{MnO}_{2}$ and $\beta-\mathrm{MnO}_{2} @ \delta-\mathrm{MnO}_{2}$ at a current density of $5 \mathrm{~A} \mathrm{~g}^{-1}$ retain $38.4,34.8$ and 37.2 of their initial values at a current density of $0.1 \mathrm{~A} \mathrm{~g}^{-1}$, indicating that these three electrodes have similar rate capabilities.

Cycling stability is another critical requirement for highperformance supercapacitor. The cycling life tests for $\beta-\mathrm{MnO}_{2}$, $\delta-\mathrm{MnO}_{2}$ and $\beta-\mathrm{MnO}_{2} @ \delta-\mathrm{MnO}_{2}$ were measured over 5000 continuous charge-discharge cycles between -0.15 to $+0.6 \mathrm{~V} v s$. $\mathrm{Hg} / \mathrm{HgO}$ at a current density of $1 \mathrm{~A} \mathrm{~g}^{-1}$ as shown in Fig. 7.

In the case of $\delta-\mathrm{MnO}_{2}$, the $C_{\mathrm{s}}$ gradually decreases with increasing cycling numbers. After 5000 cycles, $c a$. $75 \%$ of its initial capacitance is retained. Compared to $\delta-\mathrm{MnO}_{2}, \beta-\mathrm{MnO}_{2}$ and $\beta-\mathrm{MnO}_{2} @ \delta-\mathrm{MnO}_{2}$ show excellent cycling stability. After 5000 cycles, the specific capacitance retention of $\beta-\mathrm{MnO}_{2} @ \delta$ $\mathrm{MnO}_{2}$ is almost unchanged, and the coulombic efficiency of $\beta-\mathrm{MnO}_{2}$ is almost $100 \%(98.9 \%)$ as shown in Fig. 8, suggesting

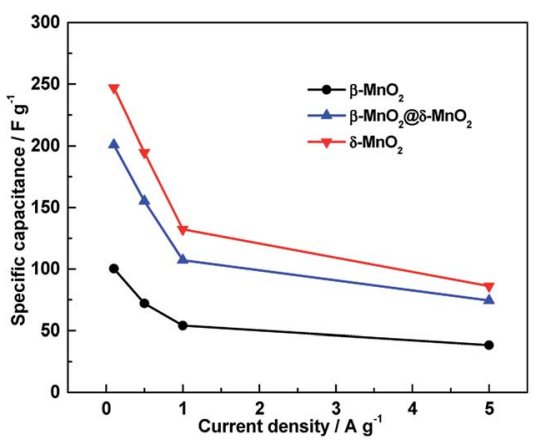

Fig. 6 Specific capacitance of $\beta-\mathrm{MnO}_{2}, \delta-\mathrm{MnO}_{2}$ and $\beta-\mathrm{MnO}_{2} \propto \delta-$ $\mathrm{MnO}_{2}$ at different current densities in $1 \mathrm{M} \mathrm{LiOH}$ electrolyte.

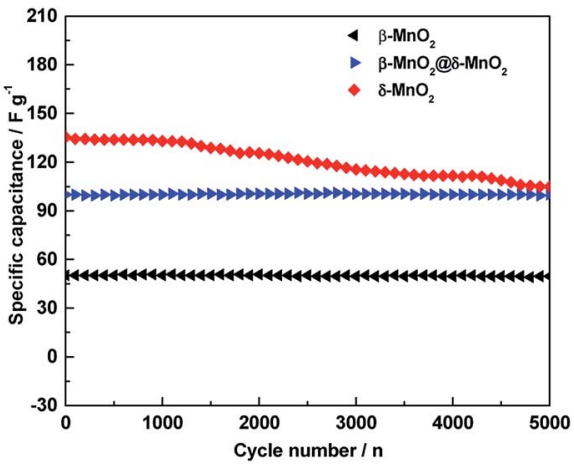

Fig. 7 Cycling stability of $\beta-\mathrm{MnO}_{2}, \delta-\mathrm{MnO}_{2}$ and $\beta-\mathrm{MnO}_{2} \propto \delta-\mathrm{MnO}_{2}$ at a current density of $1 \mathrm{~A} \mathrm{~g}^{-1}$ in $1 \mathrm{M} \mathrm{LiOH}$ electrolyte.

that the $1 \mathrm{D} \beta-\mathrm{MnO}_{2}$ pocesses superior cycling stability and the hierarchical core-shell structured $\beta-\mathrm{MnO}_{2} @ \delta-\mathrm{MnO}_{2}$ using $1 \mathrm{D}$ $\beta-\mathrm{MnO}_{2}$ as backbones, retain the cycling stability of the $1 \mathrm{D}$ $\beta-\mathrm{MnO}_{2}$. The stability of $\beta-\mathrm{MnO}_{2} @ \delta-\mathrm{MnO}_{2}$ is also much greater than that of other reported $\mathrm{MnO}_{2}$-based electrode materials, such as $\mathrm{NiCo}_{2} \mathrm{O}_{4}$-doped carbon nanofiber@ $\mathrm{MnO}_{2}$ core-sheath nanostructures, ${ }^{28}$ mesoporous $\mathrm{MnO}_{2} /$ carbon aerogel composite, ${ }^{29} \delta-\mathrm{MnO}_{2}$ nanospheres ${ }^{\mathbf{1 4}}$ and $\mathrm{MnO}_{2}$ core-shell nanowires. ${ }^{30}$ In terms of charge storage mechanism in $\mathrm{MnO}_{2}$ based electrodes,${ }^{24}$ the charge storage process is based upon the adsorption/desorption of electrolyte ions, accompanied by redox conversion between $\mathrm{Mn}^{4+}$ and $\mathrm{Mn}^{3+}$. Based on this mechanism, the excellent cyclability of $\beta-\mathrm{MnO}_{2} @ \delta-\mathrm{MnO}_{2}$ could be attributed to the fact that the Faradic redox process occurred near the electrode surface, which in turns may not possibly cause serious modification in the crystal structure and morphology of the electrode material. The cycling stability testing causes negligible damage on the structure of $\beta-\mathrm{MnO}_{2} @ \delta-\mathrm{MnO}_{2}$, resulting in the excellent cycling stability. Although the surfaces of both $\beta-\mathrm{MnO}_{2} @ \delta-\mathrm{MnO}_{2}$ and $\delta-\mathrm{MnO}_{2}$

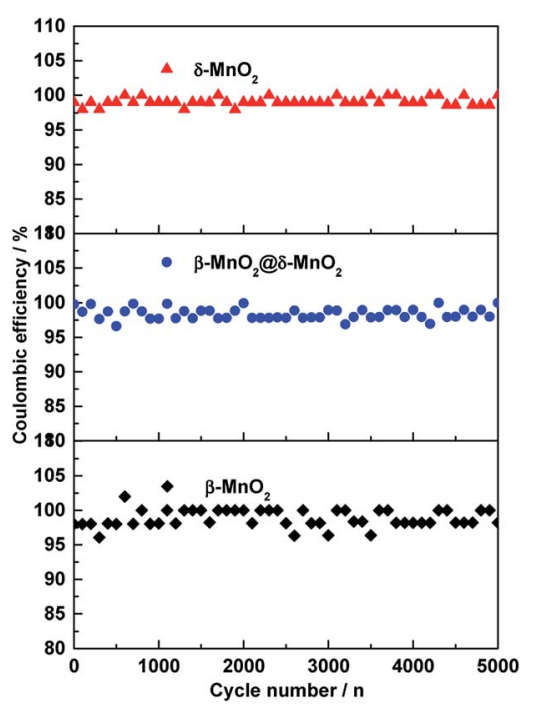

Fig. 8 Coulombic efficiency of $\beta-\mathrm{MnO}_{2}, \delta-\mathrm{MnO}_{2}$ and $\beta-\mathrm{MnO}_{2} \propto \delta$ $\mathrm{MnO}_{2}$ electrodes for 5000 cycles at a current density of $1 \mathrm{~A} \mathrm{~g}^{-1}$. 
were covered by layered structure $\delta-\mathrm{MnO}_{2}, \beta-\mathrm{MnO}_{2} @ \delta-\mathrm{MnO}_{2}$ exhibits much better stability than $\delta-\mathrm{MnO}_{2}$ since $1 \mathrm{D} \beta-\mathrm{MnO}_{2}$ can serve as a stable structural supportive backbone, which could reduce the structural damage during the reversible Faradaic redox reactions occurring in $\mathrm{MnO}_{2}$. Meanwhile, synergistic effects between core-shell structured manganese oxides with different structures and dimensions could be another reason resulting in the improved cycling stability. The excellent cyclability of $\beta-\mathrm{MnO}_{2} @ \delta-\mathrm{MnO}_{2}$ of the core-shell structure offers a promising target structure for future research.

The Nyquist plots of the electrochemical impedance spectroscopy (EIS) of $\beta-\mathrm{MnO}_{2}, \delta-\mathrm{MnO}_{2}$ and $\beta-\mathrm{MnO}_{2} @ \delta-\mathrm{MnO}_{2}$ electrodes are present in Fig. 9(A). All plots show semicircles at the higher frequency region and straight lines at the lower frequency region. The diameters of the semicircles in the highfrequency represent the Faradic charge transfer resistance of the redox reactions at the electrode-electrolyte interface. It can be observed from Fig. 9(A) that the charge transfer resistance of $\beta-\mathrm{MnO}_{2} @ \delta-\mathrm{MnO}_{2}$ is lower than that of $\beta-\mathrm{MnO}_{2}$ and $\delta-\mathrm{MnO}_{2}$, suggesting that the charge transfer is the fastest one among these three samples. The straight lines on the EIS spectra correspond to the ion diffusion process in the bulk of the active mass in the low-frequency region. The slope (of the straight line) of $\beta-\mathrm{MnO}_{2}$ is larger than that of $\beta-\mathrm{MnO}_{2} @ \delta-\mathrm{MnO}_{2}$ and $\delta$ $\mathrm{MnO}_{2}$, indicating that the ion diffusion resistance on $\beta-\mathrm{MnO}_{2}$ is the smallest among the three samples. The slope of $\beta-\mathrm{MnO}_{2} @ \delta$ $\mathrm{MnO}_{2}$ is slightly higher than that of $\delta-\mathrm{MnO}_{2}$, suggesting that $\beta$ $\mathrm{MnO}_{2}$ can provide faster ion diffusion in the bulk of the active mass and faster Faradic charge transfer on the interface of electrode-electrolyte when core-shell structured $\beta-\mathrm{MnO}_{2} @ \delta$ $\mathrm{MnO}_{2}$ is formed. Fig. 9(B) shows the EIS curves of $\beta-\mathrm{MnO}_{2} @ \delta$ $\mathrm{MnO}_{2}$ before and after 5000 cycles. It can be observed that semicircles at the higher frequency region are quite similar, indicating, after 5000 cycles, the charge transfer resistance of $\beta$ $\mathrm{MnO}_{2} @ \delta-\mathrm{MnO}_{2}$ almost didn't change. The slope of $\beta-\mathrm{MnO}_{2} @ \delta$ $\mathrm{MnO}_{2}$ is slightly smaller than that of $\beta-\mathrm{MnO}_{2} @ \delta-\mathrm{MnO}_{2}$ after 5000 cycles, suggesting that the ion diffusion resistance on $\beta$ $\mathrm{MnO}_{2} @ \delta-\mathrm{MnO}_{2}$ after 5000 cycles only increase a little bit. The EIS results clearly show that the structure of $\beta-\mathrm{MnO}_{2} @ \delta-\mathrm{MnO}_{2}$ is very stable in $1 \mathrm{M} \mathrm{LiOH}$ electrolyte. The SEM image of $\beta$ $\mathrm{MnO}_{2} @ \delta$ - $\mathrm{MnO}_{2}$ after 5000 cycles (shown in Fig. 2(D)) also confirms its structural stability.
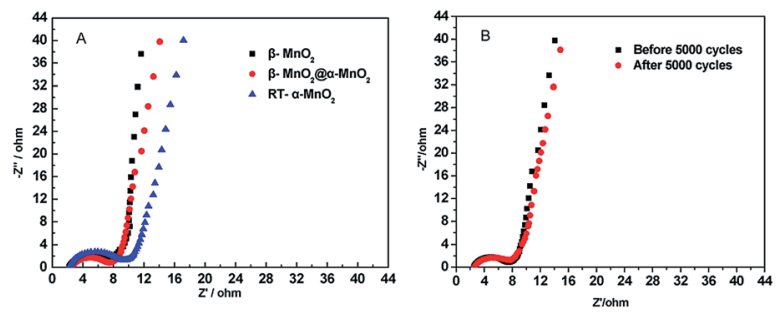

Fig. 9 (A) Electrochemical impedance spectroscopy (EIS) curves of $\beta$ $\mathrm{MnO}_{2}, \delta-\mathrm{MnO}_{2}$ and $\beta-\mathrm{MnO}_{2} \mathrm{a} \delta-\mathrm{MnO}_{2}$; (B) EIS curves of $\beta-\mathrm{MnO}_{2} \mathrm{a} \delta$ $\mathrm{MnO}_{2}$ before and after 5000 cycles.

\section{Conclusions}

In summary, a hierarchical $\beta-\mathrm{MnO}_{2} @ \delta-\mathrm{MnO}_{2}$ core-shell structure with $\beta-\mathrm{MnO}_{2}$ nano-wires as cores and layered structure $\delta$ $\mathrm{MnO}_{2}$ as shells were synthesized via a simple wet chemical method. Compared to $\delta-\mathrm{MnO}_{2}$ and $\beta-\mathrm{MnO}_{2}, \beta-\mathrm{MnO}_{2} @ \delta-\mathrm{MnO}_{2}$ shows excellent cycling stability. The capacitance retention of $\beta$ $\mathrm{MnO}_{2} @ \delta-\mathrm{MnO}_{2}$ is almost unchanged with coulombic efficiency values close to $100 \%$ after 5000 cycles. It was found that the excellent cycling stability of $\beta-\mathrm{MnO}_{2} @ \delta-\mathrm{MnO}_{2}$ arises from synergistic effects between the core-shell structured manganese oxides with different structures/dimensions and the $1 \mathrm{D} \beta-\mathrm{MnO}_{2}$ used as a stable structural supportive backbone, which could reduce the structural damage during the reversible Faradaic redox reactions occurring in $\mathrm{MnO}_{2}$. Therefore the as-prepared $\beta$ $\mathrm{MnO}_{2} @ \delta-\mathrm{MnO}_{2}$ offers a new promising cathode candidate material for alkali supercapacitors.

\section{Acknowledgements}

The authors would like to thank the National Natural Science Foundation of China (51362027, 21363022, 21606050 and 51661008) for financially supporting this work.

\section{References}

1 A. Gambou-Bosca and D. Bélanger, Electrochim. Acta, 2016, 201, 20-29.

2 T. Wang, F. Dong and Y. X. Zhang, Mater. Lett., 2016, 171, 319-322.

3 G. He, M. Qiao, W. Li, Y. Lu, T. Zhao, R. Zou, B. Li, J. A. Darr, J. Hu, M.-M. Titirici and I. P. Parkin, Adv. Sci., 2017, 4, 1600214.

4 M. Huang, F. Li, F. Dong, Y. X. Zhang and L. L. Zhang, J. Mater. Chem. A, 2015, 3, 21380-21423.

5 S. J. Zhu, J. Q. Jia, T. Wang, D. Zhao, J. Yang, F. Dong, Z. G. Shang and Y. X. Zhang, Chem. Commun., 2015, 51, 14840-14843.

6 J. Shao, X. Zhou, Q. Liu, R. Zou, W. Li, J. Yang and J. Hu, J. Mater. Chem. A, 2015, 3, 6168-6176.

7 W. Li, J. Wang, G. He, L. Yu, N. Noor, Y. Sun, X. Zhou, J. Hu and I. P. Parkin, J. Mater. Chem. A, 2017, 5, 4352-4358.

8 Z.-S. Wu, W. Ren, D.-W. Wang, F. Li, B. Liu and H.-M. Cheng, ACS Nano, 2010, 4, 5835-5842.

9 M. H. Alfaruqi, J. Gim, S. Kim, J. Song, D. T. Pham, J. Jo, Z. Xiu, V. Mathew and J. Kim, Electrochem. Commun., 2015, 60, 121-125.

10 S. Devaraj and N. Munichandraiah, J. Phys. Chem. C, 2008, 112, 4406-4417.

11 S. Bag and C. R. Raj, J. Mater. Chem. A, 2016, 4, 8384-8394. 12 A. M. Kannan, S. Bhavaraju, F. Prado, M. M. Raja and A. Manthiram, J. Electrochem. Soc., 2002, 149, A483-A492.

13 J. Cao, Q. Mao, L. Shi and Y. Qian, J. Mater. Chem., 2011, 21, 16210.

14 B. Ming, J. Li, F. Kang, G. Pang, Y. Zhang, L. Chen, J. Xu and X. Wang, J. Power Sources, 2012, 198, 428-431. 
15 M. Pang, G. Long, S. Jiang, Y. Ji, W. Han, B. Wang, X. Liu and Y. Xi, Electrochim. Acta, 2015, 161, 297-304.

16 J. Zhang, X. Yang, Y. He, Y. Bai, L. Kang, H. Xu, F. Shi, Z. Lei and Z.-H. Liu, J. Mater. Chem. A, 2016, 4, 9088-9096.

17 J. Zhu, W. Shi, N. Xiao, X. Rui, H. Tan, X. Lu, H. H. Hng, J. Ma and Q. Yan, ACS Appl. Mater. Interfaces, 2012, 4, 2769-2774.

18 T. T. Truong, Y. Liu, Y. Ren, L. Trahey and Y. Sun, ACS Nano, 2012, 6, 8067-8077.

19 S. W. Lee, B. M. Gallant, H. R. Byon, P. T. Hammond and Y. Shao-Horn, Energy Environ. Sci., 2011, 4, 1972-1985.

20 G. Zhu, H. Li, L. Deng and Z.-H. Liu, Mater. Lett., 2010, 64, 1763-1765.

21 X. Zhang, X. Chang, N. Chen, K. Wang, L. Kang and Z.-h. Liu, J. Mater. Sci., 2012, 47, 999-1003.

22 Z. Jia, J. Wang, Y. Wang, B. Li, B. Wang, T. Qi and X. Wang, J. Mater. Sci. Technol., 2016, 32, 147-152.
23 S. Brunauer, L. S. Deming, W. E. Deming and E. Teller, J. Am. Chem. Soc., 1940, 62, 1723-1733.

24 Q. Qu, P. Zhang, B. Wang, Y. Chen, S. Tian, Y. Wu and R. Holze, J. Phys. Chem. C, 2009, 113, 14020-14027.

25 K. Wang, C. Zhao, S. Min and X. Qian, Electrochim. Acta, 2015, 165, 314-322.

26 Y. Hu, J. Wang, X. Jiang, Y. Zheng and Z. Chen, Appl. Surf. Sci., 2013, 271, 193-201.

27 J. An, X. Peng, S. Xu, Z. Xu and J. Wang, RSC Adv., 2015, 5, 97080-97088.

28 F. Lai, Y.-E. Miao, Y. Huang, T.-S. Chung and T. Liu, J. Phys. Chem. C, 2015, 119, 13442-13450.

29 G.-R. Li, Z.-P. Feng, Y.-N. Ou, D. Wu, R. Fu and Y.-X. Tong, Langmuir, 2010, 26, 2209-2213.

30 X. Zhang, J. Ma, W. Yang, Z. Gao, J. Wang, Q. Liu, J. Liu and X. Jing, CrystEngComm, 2014, 16, 4016. 